Sastré Employee of: Novartis Farmacéutica Spain, Pedro Plazuelo-Ramos: None declared, Jordi Gratacos-Masmitja Grant/research support from: Abbvie, BMS, Lilly, MSD, Novartis, Pfizer, Roche, and UCB.

DOI: 10.1136/annrheumdis-2021-eular.2537

\begin{tabular}{|l|l|}
\hline POS0993 & THE IMPORTANCE OF PHYSICAL ACTIVITY IN \\
& RELATION TO BEING OVERWEIGHT/OBESE WITH \\
& AXIAL SPONDYLOARTHRITIS. RESULTS FROM THE \\
& SPANISH ATLAS
\end{tabular}

M. Garrido-Cumbrera ${ }^{1}$, E. Collantes-Estevez ${ }^{2}$, V. Navarro-Compán ${ }^{3}$, P. ZarcoMontejo $^{4}$, J. Correa-Fernández ${ }^{1}$, C. Sastré ${ }^{5}$, P. Plazuelo-Ramos ${ }^{6}$, J. GratacosMasmitja ${ }^{7}$ on behalf of Atlas working group. ${ }^{1}$ Universidad de Sevilla, Health \& Territory Research (HTR), Seville, Spain; ${ }^{2}$ Reina Sofia University Hospital, Rheumatology Department, Cordova, Spain; ${ }^{3}$ Hospital Universitario La Paz, IdiPaz, Madrid, Spain; ${ }^{4}$ Hospital Universitario Fundación Alcorcón, Rheumatology Department, Madrid, Spain; ${ }^{5}$ Novartis Farmacéutica Spain, Immunology, Hepatology and Dermatology, Barcelona, Spain; ${ }^{6}$ Spanish Federation of Spondyloarthritis Associations (CEADE), Presidency, Madrid, Spain; ${ }^{7}$ Hospital Universitaria Parc Taulí, Rheumatology Department, Barcelona, Spain

Background: Evidence on the negative effects of being overweight/obese on the health outcomes of patients with axial spondyloarthritis (axSpA) is increasing. Objectives: This study aimed to identify associations between Body Mass Index (BMI) categories and disease activity, functioning, quality of life, and mental health in a large sample of axSpA patients.

Methods: In 2016, a sample of 680 unselected patients with axSpA participated in the Atlas of Axial Spondyloarthritis in Spain through an online survey. The sample was divided in two groups: 1) Patients with a BMI of 18.5 to $<25 \mathrm{Kg} / \mathrm{m} 2$ (normal weight), and 2) Patients with a BMI of $\geq 25 \mathrm{Kg} / \mathrm{m} 2$ (overweight/obesity), excluding the underweight category (BMI $<18.5 \mathrm{Kg} / \mathrm{m} 2$ ). The Mann-Whitney and Pearson's chi-square tests were used to analyse possible relationships between independent sociodemographic characteristics, employment, lifestyle, patient-reported outcomes, and comorbidity variables with those who are overweight/ obese. Univariate and multivariate binary logistic regression was used to determine the association of the possible factors with those who are overweight/obese. Results: Of the 663 patients analysed, the mean age was 45.9 years, $51.4 \%$ were female, $37.0 \%$ had a university degree, and $72.5 \%$ were married. The prevalence of overweight/obese patients was $53.4 \%$ compared to $46.6 \%$ who were of a normal weight. The patients with the highest prevalence of being overweight/obese were older (49.3 vs $42.0, p<0.001)$, with no university education $(59.8 \%$ vs $42.4 \%$ of university, $p<0.001)$, often widowers $(75.0 \%$ vs $30.8 \%$ of single people, $p<0.001)$, and reported membership of patient organisations $(61.7 \%$ vs $46.6 \%, p<0.001)$. With respect to patients of normal weight, those who were overweight/obese presented greater spinal stiffness $(8.2$ vs $6.6, p<0.001)$ and a longer diagnostic delay $(9.2$ vs $7.8, p=0.005$ ). In addition, patients who were overweight/obese were more likely physically inactive $(63.7 \%$ vs $36.3 \%, p=0.007)$. In the multivariable binary logistic regression analysis, the qualitative factors associated with the presence of being overweight/obese were physical inactivity $(\mathrm{OR}=2.40)$ and males $(\mathrm{OR}=1.81)$, while the quantitative factor most associated with the presence of being overweight/ obese were greater spinal stiffness $(B=0.121)$ and older in age $(B=0.052)$ (Table 1).

Table 1. Logistic regression to analyses factor associated with being overweight/obese $(\mathrm{N}=469)$

\begin{tabular}{|c|c|c|c|c|}
\hline & \multicolumn{2}{|c|}{$\begin{array}{l}\text { Univariate logistic } \\
\text { analysis }\end{array}$} & \multicolumn{2}{|c|}{$\begin{array}{l}\text { Multivariate logistic } \\
\text { analysis }\end{array}$} \\
\hline & OR & p-value ${ }^{1}$ & OR & p-value ${ }^{1}$ \\
\hline \multicolumn{5}{|l|}{ Qualitative factors } \\
\hline Gender. Male & 2.376 & $<0.001$ & 1.811 & 0.005 \\
\hline Educational level. No university & 2.018 & $<0.001$ & 1.188 & 0.422 \\
\hline Marital Status. Widowed & 2.647 & 0.235 & NA & NA \\
\hline Member of PAGs. Yes & 1.851 & $<0.001$ & 1.095 & 0.680 \\
\hline Employment. Retired / early retirement & 4.414 & $<0.001$ & 1.732 & 0.195 \\
\hline Physical activity. No & 1.703 & 0.007 & 2.400 & 0.038 \\
\hline Quantitative factors & B & p-value ${ }^{2}$ & $\mathrm{~B}$ & p-value ${ }^{2}$ \\
\hline Age & 0.070 & $<0.001$ & 0.052 & $<0.001$ \\
\hline Spinal Stiffness (3-12) & 0.220 & $<0.001$ & 0.121 & 0.004 \\
\hline Diagnostic Delay & 0.024 & 0.035 & 0.008 & 0.568 \\
\hline
\end{tabular}

${ }^{1} \mathrm{p}$-value for test $\mathrm{H}_{0}: O R=1{ }^{2} \mathrm{p}$-value for test $\mathrm{H}_{0}: \mathrm{B}=0$.

Conclusion: Being overweight/obese is a common comorbidity among patients with axSpA. The lack of physical activity, male gender, higher spinal stiffness, and older age increase the probability of prevalence of being overweight/obese. Physicians should encourage physical activity in patients with axSpA, especially among men and older people to prevent the factors of being overweight/obese. Acknowledgements: This study was supported by Novartis Spain. The authors would like to thank all patients who participated in the study.
Disclosure of Interests: Marco Garrido-Cumbrera: None declared, Eduardo Collantes-Estevez Grant/research support from: Abbvie, BMS, Lilly, MSD, Novartis, Pfizer, Roche, and UCB, Victoria Navarro-Compán Grant/research support from: Abbvie, BMS, Lilly, MSD, Novartis, Pfizer, Roche, and UCB, Pedro Zarco-Montejo: None declared, José Correa-Fernández: None declared, Carlos Sastré Employee of: Novartis Farmacéutica Spain, Pedro Plazuelo-Ramos: None declared, Jordi Gratacos-Masmitja Grant/research support from: Abbvie, BMS, Lilly, MSD, Novartis, Pfizer, Roche, and UCB.

DOI: 10.1136/annrheumdis-2021-eular.2545

\section{POS0994 NON-RHEUMATOLOGISTS FIND IT DIFFICULT TO IDENTIFY AXIAL SPONDYLOARTHRITIS IN WOMEN AND YOUNG PEOPLE. RESULTS FROM THE SPANISH ATLAS}

M. Garrido-Cumbrera ${ }^{1}$, V. Navarro-Compán ${ }^{2}$, J. Gratacos-Masmitja ${ }^{3}$, P. ZarcoMontejo $^{4}$, J. Correa-Fernández ${ }^{1}$, C. Sastré ${ }^{\text {, P. Plazuelo-Ramos }}{ }^{6}$, E. CollantesEstevez ${ }^{7}$ on behalf of Atlas working group. ${ }^{1}$ Universidad de Sevilla, Health \& Territory Research (HTR), Seville, Spain; ${ }^{2}$ Hospital Universitario La Paz, IdiPaz, Madrid, Spain; ${ }^{3}$ Hospital Universitaria Parc Tauli, Rheumatology Department, Barcelona, Spain; ${ }^{4}$ Hospital Universitario Fundación Alcorcón, Rheumatology Department, Madrid, Spain; ${ }^{5}$ Novartis Farmacéutica Spain, Immunology, Hepatology and Dermatology, Barcelona, Spain; ${ }^{6}$ Spanish Federation of Spondyloarthritis Associations (CEADE), Presidency, Madrid, Spain: ${ }^{7}$ Reina Sofia University Hospital, Rheumatology Department, Cordova, Spain

Background: Delayed diagnosis in axial spondyloarthritis (axSpA) in Spain seems to be influenced by the patient diagnostic pathway. In particular, not all patients are diagnosed by rheumatologists, the profession better suited to make an axSpA diagnosis.

Objectives: The aim of this study is to evaluate the differences between patients diagnosed by a rheumatologist and those diagnosed by other healthcare professionals (HCPs)

Methods: In 2016, a sample of 680 unselected patients with axSpA participated in the Atlas of Axial Spondyloarthritis in Spain, an online survey. The sample was divided into: 1) Patients diagnosed by rheumatologists and 2) Non-Rheumatologist diagnosis including general practitioner, orthopaedic specialist, and physiotherapist. The Mann-Whitney and Pearson's chi-square tests were used to assess possible differences between both groups in sociodemographic characteristics, employment, lifestyle, patient-reported outcomes, and comorbidities. Univariate and multivariate binary logistic regression was used to analyse the possible factors associated with diagnosis by a non-Rheumatologist.

Results: A total of 522 axSpA patients participated in this study: the mean age was 45.3 years, $51.0 \%$ were female, $38.5 \%$ had a university degree, and $71.6 \%$ and were married. Prior to diagnosis, axSpA patients visited different HCPs such as a General Practitioner (GP) (88.5\%), orthopaedic specialists $(71.6 \%)$, rheumatologists $(71.0 \%)$, and physiotherapists $(46.9 \%)$. The greatest number of visits (mean median) were made to physiotherapists $(3.4,3)$, followed by orthopaedic specialists $(3.0,2)$, rheumatologists $(2.0,1)$ and GPs $(2.6,2)$. The majority $(81.4 \%)$ of patients were diagnosed by a rheumatologist, while $18.6 \%$ received their diagnosis from a non-rheumatologist (10.9\% orthopaedic specialist, $7.3 \%$ general practitioner, and $0.4 \%$ physiotherapist). With respect to other specialists such as the GP, orthopaedic specialist or physiotherapist, patients diagnosed by the rheumatologist were younger ( 44.3 vs $49.5, p<0.001$ ), more frequently female $(54.8 \%$ vs $45.2 \%$ of male, $p<0.001)$, with worse mental health ( 5.9 vs $4.8, p=0.039$ ), who visited more professionals before being diagnosed ( 3.0 vs $2.5, p=0.001$ ), were more frequently smokers $(40.2 \%$ vs $26.0 \%, p=0.010)$ and used more biologicals $(45.9 \%$ vs $33.0 \%, p=0.021)$. In the multivariate binary logistic regression, the qualitative factors associated with diagnosis by non-rheumatologists are males $(\mathrm{OR}=1.80)$, and the quantitative factors associated with the diagnosis by non-rheumatologists are older age $(B=0.027$; Table 1$)$.

Table 1. Logistic regression to analyses factor associated with non-rheumatologist diagnosis $(\mathrm{N}=440)$

\begin{tabular}{|c|c|c|c|c|}
\hline & \multicolumn{2}{|c|}{$\begin{array}{l}\text { Univariate logistic } \\
\text { analysis* }\end{array}$} & \multicolumn{2}{|c|}{$\begin{array}{l}\text { Multivariate logistic } \\
\text { analysis }{ }^{\star}\end{array}$} \\
\hline & OR & p-value ${ }^{2}$ & OR & $p$-value ${ }^{2}$ \\
\hline \multicolumn{5}{|l|}{ Qualitative factors } \\
\hline Gender. Female $^{1}$ & 2.354 & $<0.001$ & 1.797 & 0.030 \\
\hline Smoking. Yes & 0.523 & 0.010 & 0.611 & 0.095 \\
\hline Used of Biologics. Yes & 0.581 & 0.022 & 0.640 & 0.086 \\
\hline Quantitative factors & B & $p$-value ${ }^{3}$ & B & p-value ${ }^{3}$ \\
\hline Age, in years & 0.044 & $<0.001$ & 0.027 & 0.028 \\
\hline GHQ-12 (0-12) & $\begin{array}{l}-0.059 \\
-059\end{array}$ & 0.038 & 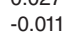 & 0.721 \\
\hline Number of HCPs seen before diagnosis & -0.294 & 0.001 & -0.153 & 0.151 \\
\hline
\end{tabular}

${ }^{*}$ Reference category of the dependent variable: Non-Rheumatologist; ${ }^{1}$ Female vs male ${ }^{2} \mathrm{p}$-value for test $\mathrm{H}_{0}: \mathrm{OR}=1{ }^{3} \mathrm{p}$-value for test $\mathrm{H}_{0}: \mathrm{B}=0$ 